\title{
Analysis of Traceability Optimization and Shareholder's Profit for Efficient Supply Chain Operation under Product Recall Crisis
}

\author{
Muhammad Saad Memon, ${ }^{1,2}$ Young Hae Lee, ${ }^{1}$ and Sonia Irshad Mari ${ }^{1,2}$ \\ ${ }^{1}$ Department of Industrial and Management Engineering, Hanyang University, Ansan 15588, Republic of Korea \\ ${ }^{2}$ Department of Industrial Engineering and Management, Mehran University of Engineering and Technology, \\ Jamshoro 76062, Pakistan \\ Correspondence should be addressed to Young Hae Lee; yhlee@hanyang.ac.kr
}

Received 2 June 2015; Revised 25 October 2015; Accepted 26 October 2015

Academic Editor: Peide Liu

Copyright (C) 2015 Muhammad Saad Memon et al. This is an open access article distributed under the Creative Commons Attribution License, which permits unrestricted use, distribution, and reproduction in any medium, provided the original work is properly cited.

\begin{abstract}
Product recall gains considerable importance in recent times; the reason may be the huge losses faced by manufacturers because of product recall issues. Furthermore, the revenue of the firm is immensely affected as a result of product recall, which may lead to serious outcomes. Huge recall cost (such as repairing or destroying the recalled products and cost of notification) occurs as a result of large recall. Therefore, in order to minimize the quantity and probability of recalls the traceability systems are widely used and considered as a necessary part of product safety strategies. However, from literature it is clear that manufacturers are still struggling to obtain the significant results. This study helps the managers to understand the importance of recall cost by analysing its impact on shareholders profit. Keeping in view the importance of problem, the paper proposed an integrated optimization model to minimize the expected loss to shareholders in recall crisis using batch dispersion methodology. The analysed results show that reduction in traceability level increases the expected shareholders losses while decreasing the operational costs. This will help managers to optimally set the production batch sizes in order to reduce the product recall impact.
\end{abstract}

\section{Introduction}

Manufacturers are facing immense problems regarding product safety which leads to huge product recalls. The United Sates Department of Agriculture reported 82 recalls which contained around 3,475,115 pounds of meat in year 2012 [1]. Food Standards Australia reported around 60 recalls of food products in 2012, more than the average of the past year [2]. Other than food the higher recalls results are shown in consumer products. According to the US Consumer Product Safety Commission, 5,095 products were recalled in 2013 [3]. These statistics show that producers are still facing recall crises. Huge recall cost (such as repairing or destroying the recalled products and cost of notification) occurs as a result of large recall. Manufacturers always faced problems in recalling defected products because of poor traceability systems. If the design of traceability system is appropriately effective and efficient then it significantly helps the production systems in managing the product safety issues and recall crisis. In order to minimize the quantity and probability of recalls the traceability systems are widely used and considered as a necessary part of product safety strategies. However, from literature it is clear that still manufacturers are struggling to get (obtain) the (significant) substantial results. Recall statistics showed that microbial contamination is the leading reason of all recalls followed by contamination of foreign material in the finished products. Practitioners have always tried to trace raw material batches contaminated by microbial contamination in food industry and defected component batches in assembly lines but they failed because of nonoptimized traceability systems. Also, it is very costly for companies to refund the customer's money or replace defected products. At times the situation becomes worse when defected products lead to customer health problems or injuries. The US Consumer Product Safety 
Commission (CPSC) indicates that the total recall cost in US is more than $\$ 700$ billion each year just for consumer products [4]. Most companies now rely on insurance to cover defined cost involved in recalls. However, companies face hard times when insurance cannot be claimed due to the severity of product recall, especially the recall of unsafe and contaminated products.

According to the US Food and Drug Authority (USFDA), company's stock prices decline by $22 \%$ within two weeks after recall announcement. The average cost of recall in US companies is around $\$ 10$ million. The revenue of the firm is immensely affected as a result of product recall [5], which may lead to serious outcomes. Furthermore, Kini et al. [6] found that large amount of capital is invested during recall crisis, which further burden shareholders.

Owing to importance of issue, this paper develops a model to minimize the direct cost of recall using batch dispersion methodology and aiming to reduce the loss to shareholders profit. This is due to fact that many studies suggest negative impact on market shares in recall crisis [7]. It is found from studies that minimization of recall cost by batch dispersion methodology increases the operational costs (i.e., setup and holding costs); due to this reason large number of firms ignore the importance of recall cost while designing the production system. This study helps the managers to understand the importance of recall cost by analysing its impact on shareholders profit as studies suggest that large number of recall causes significant decline in sales and brand image and adverse effects on stock price [6]. The paper answers the following questions: (i) What should be the batch size? (ii) How much of each raw material batch is used in a finished product batch? (iii) What will be the expected recall cost? (iv) What will be the expected loss to shareholders in case of product recall?

\section{Related Works}

In today's global market, the supply chain presents significant risk management challenges. Having an appropriate traceability and recall plan in place is critical to managing supply chain risks. The ability to track products through all stages of the supply chain has always been important for companies, but in the event of a product recall, having an efficient system in place is critical [8].

Traceability will help to build trust and in the establishment of long-term relationships among supply chain partners and consumers [10]. Advances in track and trace technologies such as RFID is giving companies more visibility to the supply chain and can be beneficial in a product recall $[11,12]$. Improved product and manufacturing process designs will minimize likelihood of quality issues and product recalls [8]. Recalls have several costs associated with them, both direct and indirect [13]. Table 1 lists direct and indirect cost drivers adapted from [8]. The manufacturers bear the huge direct cost [14] and indirect cost.

Many researchers focus on traceability systems in order to increase the product safety. Large parts of literature consist of traceability technology while much less literature
TABLE 1: Direct and indirect recall costs.

\begin{tabular}{ll}
\hline Direct recall costs & Indirect recall costs \\
\hline Notification costs & Loss of market share \\
Loss of sales & Subsequent loss of sales \\
Cost to maintain business & Negative impact on brand \\
interruption & image \\
Inventory losses & Cost to rehabilitate image \\
Cost of refund/compensation & Collapse of organization \\
Logistics costs & Negative impact on morale \\
Fines/lawsuits & Cost to rehabilitate \\
\hline
\end{tabular}

is available on manufacturing methodologies needed for efficient utilization of traceability system. To the best of our knowledge, Dupuy et al. [15] proposed a batch dispersion methodology to optimize the traceability system in order to reduce the impact of recall. Wang et al. [16] used a batch dispersion methodology to optimize the batch size considering traceability factor. Rong and Grunow [17] used the same methodology to optimize the chain dispersion in food distribution system. Memon et al. [18] also used a batch dispersion methodology considering a more robust recall cost management in three-stage multiprocured bill of material (BOM). Ferrier and Buzby [13] developed an economic model for sampling beef trim to equate marginal benefits and costs.

All of above researches focus on optimizing batch and total cost considering traceability system. However, it is also very important to analyse the impact of traceability optimization on shareholders profit. Traceability optimization refers to how well recalled products are retrieved, which helps to minimize the impact of recall event. Large number of studies suggest that firms experience significant decline in firm's stock price [5]. Shin et al. [7] show that minor recalls may produce no damage to the sales; however, major recalls show strong evidence of negative impact on stock price. This shows that large recall cost leads to enormous loss to shareholder profit; for example, Toyota observed 34\% decline in brand market share after 2007 and 2010 recalls [19]; Freedman et al. [20] observed 30\% decline in sales of toys after 2007 major toy recall events. Kini et al. [6] show that recalling firms experience a significant decline in sales for one to two years after recall event. They also found that firms are attempting to invest huge capital in advertisement to repair tarnished brand image which further burdens the shareholders wealth. Chen and Nguyen [21] found that shareholders wealth is affected after a product recall and investors negatively respond to recalling firms with previous evidence; such losses further lead to a negative long-term stock market performance [22]. This shows that stock price of recalling firms continuously declines after recall events; however, some studies observed that recall announcement has positive impact on future sales due to fulfilment of corporate social responsibility [23]. Although prior literature showed mixed results about product recall and sales, it is clear that product recall has some impact on shareholders' wealth. 


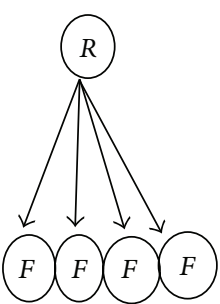

(a)

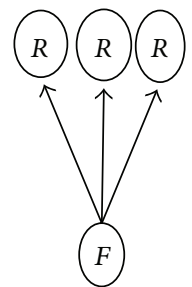

(b)
3 material batches

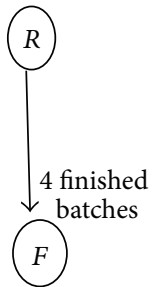

(c)
FIGURE 1: Simple batch dispersion concept.

To the best of authors knowledge, this study is the first proposal and demonstration of an integrated optimization model which minimizes the expected loss to shareholders in recall crisis using batch dispersion methodology. The following section provides basic introduction to traceability optimization and batch dispersion methodology.

2.1. Traceability Optimization. In order to evaluate the accuracy of the traceability in the production process, Dupuy et al. [15] introduce new measures: downward dispersion, upward dispersion, and batch dispersion in food production as shown in Figure 1. However these measures are also applicable to all type of batch production systems. The downward dispersion of a raw material batch is the number of finished product batches which contain parts of this raw material batch. For example, a raw material batch is used in 4 batches of the finished product (see Figure 1(a)). The upward dispersion of a finished product batch is the number of different raw material batches used to produce this batch. For example, a finished product batch consists of 3 batches of raw materials (see Figure 1(b)). The total dispersion is the summation of all downward and upward dispersions and is called batch dispersion (see Figure 1(c)). Traceability is major instrument to reduce the negative impact of recall, because it helps to quickly trace the recalling product and boost recall communication. Traceability system enables the firms to track each sold unit or product in supply chain operation [24]; however, increment in batch dispersion causes failure of traceability system. For example, ConAgra had revised its recall of contaminated peanut butter twice in 2007 because of inaccurate volume and location information [24]. This shows that despite having traceability system companies cannot accurately recall their products due to high batch dispersion.

In practice, batch numbers are assigned to the material and semifinished products to identify throughout the supply chain. If a safety problem due to raw material batch is identified in finished product then all the finished product batches containing this raw material have to be identified and recalled. In many types of industries where batch production process is carried out, raw material batches from different suppliers with different prices and quality attributes are often mixed together. This is usually known as a batch dispersion problem which concerns relevant disassembling and assembling processes in the production [15].

\section{Proposed Integrated Optimization Model}

The aim of proposed model is to minimize the loss of shareholders profit in recall crisis by minimizing the expected recall cost with the integration of a traceability factor. In order to increase the product safety or reduce the impact of a recall, manufacturers have to incorporate traceability in their process in order to reduce batch dispersion. Probability of recall will be increased with the increase in batch size because larger batch size requires more raw material batches, which increases the chances of contamination. Traceability system effectiveness can be measured by amount of decrease in frequency of product recall and the amount of product to be withdrawn in recall crisis. The proposed model is solved for three-stage bill of material as represented in Figure 2. The model also incorporates the operational costs, that is, setup cost and holding cost, because it is found from studies that minimizing batch dispersion or increasing traceability level requires large number of production setups, hence increasing the setup cost. Thus, inclusion of these costs is due to fact that optimizing traceability levels has negative correlation with these costs. Notations used in model are shown in Notations of Traceability Model.

The production setups cost is assumed to be fixed in proposed economic production quantity (EPQ). The EPQ balances setup and inventory costs in order to minimize total costs. Here, the production setup cost in a planning period is described in

$$
C^{\text {Setup }}=\frac{D}{Q} \text { USC. }
$$

In many cases, products cannot be delivered until the whole batch is produced for quality assurance purposes [16]. To calculate the holding cost of the finished product, the gathered inventory during production cannot be delivered until the whole batch is completed. When the inventory from previous batch is exhausted and is ready for the next delivery, the next batch production resumes (see Figure 3). In this model, only holding cost of finished product inventory is considered. The average product inventory level can be calculated by obtaining the triangle area and staircase area (see Figure 3) and dividing it by total cycle time $n t$ as shown in (2). As the frequency of delivery is constant, therefore integer variable $n$ can be replaced by $Q / x$. Consider

$$
I_{\mathrm{AVG}}=\frac{Q^{2}}{2 P \cdot n t}+\frac{(n-1) x}{2} .
$$

The total inventory holding cost can be estimated by

$$
C^{\text {Holding }}=\frac{Q x H}{2 P t}+\frac{Q}{H}-\frac{x H}{2} .
$$

The major aim of this paper is to incorporate traceability system in existing batch production systems, which would create additional costs for producers. Probability of recall will be increased with an increase in batch size because a larger batch size requires more raw material batches which increases the chance of contamination. Traceability system effectiveness can be measured by amount of decrease in 


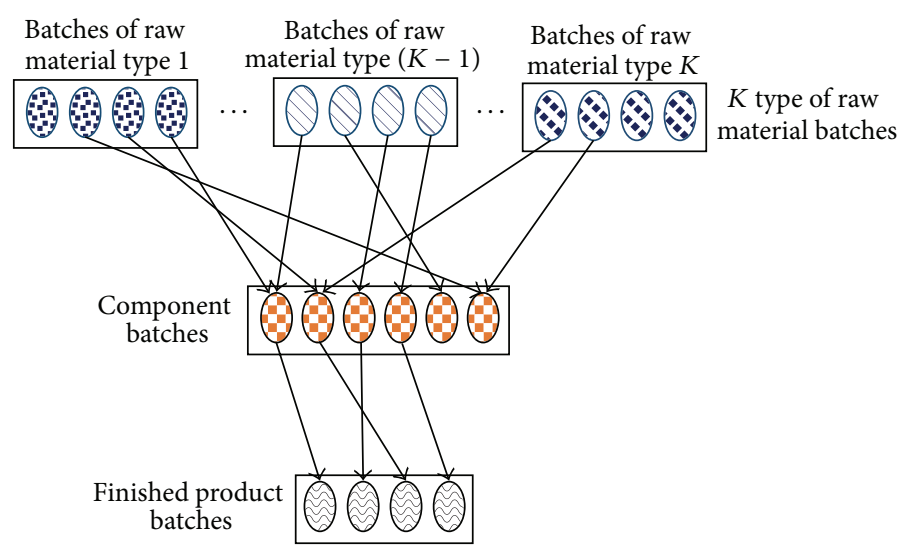

FIGURE 2: Graphical model of 3-level batch dispersion.

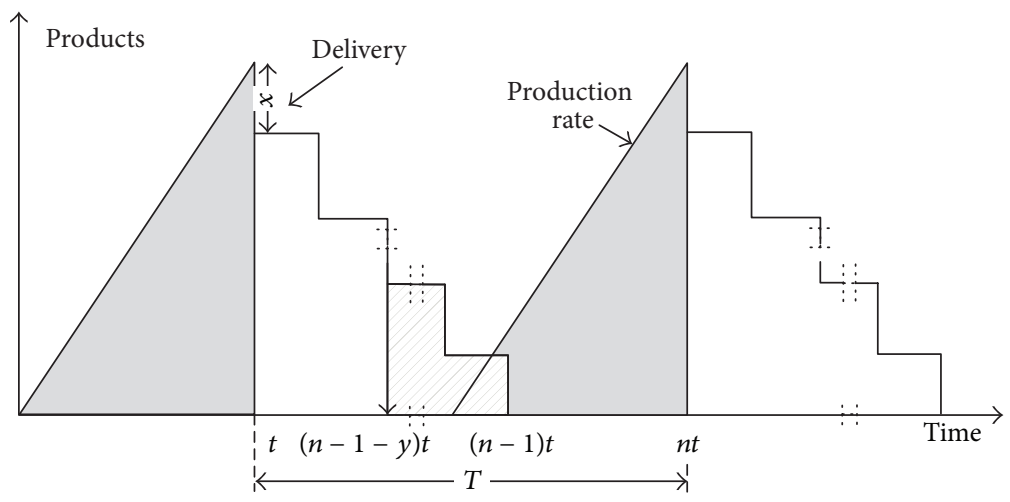

Figure 3: Product inventory level with respect to time (Adopted from [25]).

frequency of product recall and the amount of product to be withdrawn in a recall crisis. We consider the two utmost important recall costs in this model, which include recall notification cost and product retrieval cost together with value of product. Product retrieval cost depends on the quantity of recalled products, whereas product notification cost is a fixed cost incurred in recall crises. In this model, we only consider the recall shipment cost and holding cost of recalled items as the product retrieval cost; the expected recall cost for three-stage BOM (see Figure 2) can be described as

$$
\begin{aligned}
C^{\text {Recall }}= & \sum_{k} \sum_{i}^{S} \sum_{j} X r c \sum_{j} \sum_{f} X c f \\
& \cdot\left\{D\left(R_{F}+\mathrm{CRH}+\mathrm{CS}\right)+\mathrm{CN}\right\},
\end{aligned}
$$

where

$$
S=\frac{Q B_{R C}(K)}{Q_{K}} .
$$

The integer variable $S$ in (4) depends on the finished product batch size. If batch size increases, the more $K$ th type of raw material batches will be required to fulfill the finished product batch size. Naturally, if more raw material batches are used in each batch of the finished product, then it will be very difficult to trace the source of the problem in the final finished product batch. This type of problem widely occurs in the food and pharmaceutical industries. In consumer product industries like toys and automobiles, manufacturers randomly assembled components from different suppliers in the same finished product batch which again leads to the same problem of increased complexity in traceability and will lead to high expected recall cost. This problem can be easily solved using a batch dispersion methodology by minimizing the expected recall cost as shown in (4).

The total cost of production also includes the raw material cost. It is necessary to calculate the raw material cost or all procured materials cost, because different types of procured materials may come from different suppliers and may have different price and product safety risk attributes. In practice, these batches are often mixed together in finished product batch to balance cost and quality. The cost of individual procured material batches can be calculated by multiplying the unit price with batch quantity. Therefore, the total material cost for a production cycle can be given by

$$
C^{\text {Material }}=\frac{D}{Q}\left(\sum_{k} \sum_{i}^{S} \sum_{j} X r c \sum_{j} \sum_{f} X c f V_{i, k}\right) .
$$


3.1. Shareholder Profit. The major aim of the proposed model is to incorporate shareholders profit. The shareholders profit depends on the firm's performance: if the performance is ineffective then there will be more probability of a product recall. During a recall crisis, firms face two types of costs: direct cost and indirect cost, but here we only consider the direct costs as these costs affect the shareholder's profit. It is hoped that our results will be useful for practitioners to assess the impact of recall on profit. In order to determine the impact of recall on shareholders profit we assume that there will be a recall or no recall in next month. If a recall will occur then the expected recall cost $C^{\text {Recall }}$ will be imposed to shareholders as expected revenue of a firm suffering a product recall tends to decline for a period or, perhaps, forever [26]. Therefore, the firm's stock price or the value of a stock at the end of the month will be as shown in (7) if no recall occurs and as shown in (8) if a recall occurs:

$$
\begin{aligned}
S^{N R} & =\sum_{t}^{\infty} \frac{e_{t}}{(1+r)^{t}} \quad \text { (If no recall occurs), } \\
S^{R} & =\sum_{t}^{\infty} \frac{e_{t}}{(1+r)^{t}}-C^{\text {Recall }} \quad \text { (If recall occurs). }
\end{aligned}
$$

In the above model, it is assumed that number of stock shares are fixed and estimated earnings per share in period $t$ are $e_{t}$. Expected future earnings will be assumed by a constant interest rate $r$. The value of share of stock is familiar concept that value of stock is the present value of expected future earnings per share [26].

The value of a stock at the month beginning is the present value of future profit. We assumed that there is probability $p$ for occurring recall in the next period. The probability $p$ that a product recall occurs must be assessed and included in the decision-making process [27]. Probability of recall can be assessed by risk assessment techniques such risk exposure. Risk exposure can be used as probability of recalls whenever the firm has access to reliable statistics, for example, process risk model developed by Cassin et al. [28] to quantify the risk exposure of E. coli O175:H7 in beef hamburgers. The knowledge of risk exposure could be explicitly taken into account in the formulation of the ensuing optimization problem [29]. Therefore stock price at the beginning of the period is estimated in

$$
S_{b}=p\left(\sum_{t}^{\infty} \frac{e_{t}}{(1+r)^{t}}-C^{\text {Recall }}\right)+(1-p) \sum_{t}^{\infty} \frac{e_{t}}{(1+r)^{t}} .
$$

Thus, if a recall occurs in the next period, then the expected loss in shareholders profit $\left(L^{\mathrm{SP}}\right)$ will be as in (10), where $N$ represents the number of outstanding shares:

$$
\begin{aligned}
L^{\mathrm{SP}} & =N\left\{p\left(\sum_{t}^{\infty} \frac{e_{t}}{(1+r)^{t}}-C^{\text {Recall }}\right)\right. \\
& \left.+(1-p) \sum_{t}^{\infty} \frac{e_{t}}{(1+r)^{t}}-\left(\sum_{t}^{\infty} \frac{e_{t}}{(1+r)^{t}}-p C^{\text {Recall }}\right)\right\} .
\end{aligned}
$$

TABLE 2: Input parameters of traceability model.

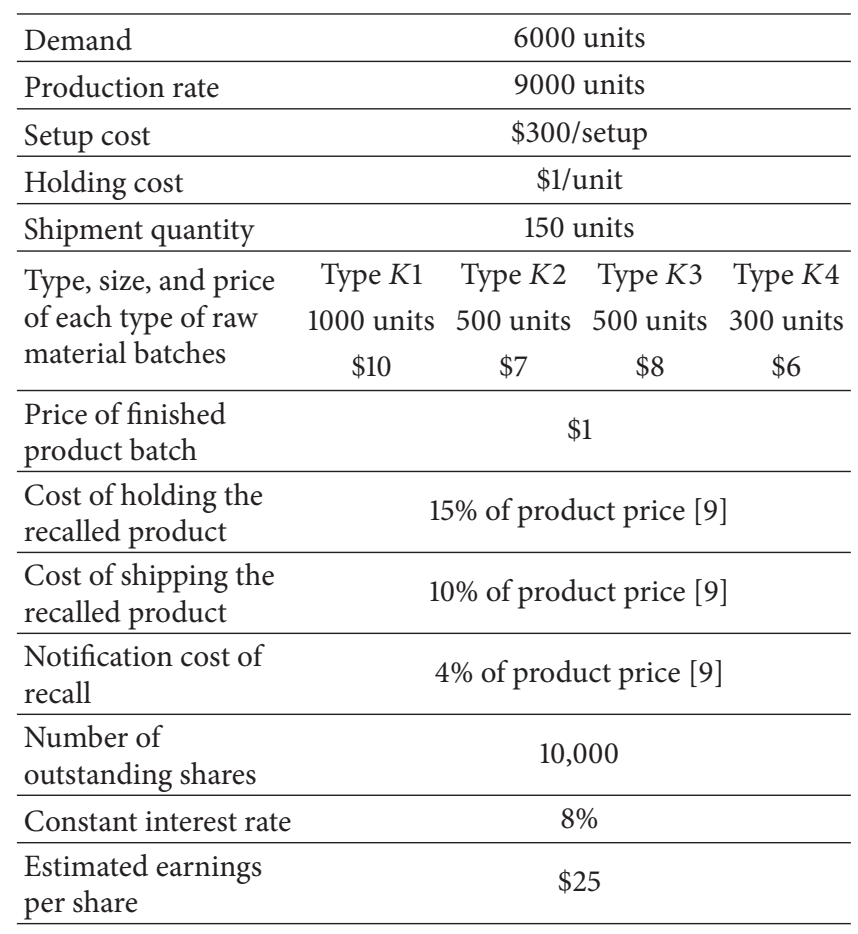

The integrated optimization model for minimizing expected loss in shareholders profit and other operational costs expressed:

$$
\begin{aligned}
\text { Minimize } & Z \\
= & \underbrace{L^{\mathrm{SP}}}_{\text {loss to shareholder profit }} \\
& +\underbrace{C^{\text {Material }}+C^{\text {Holding }}+C^{\text {Setup }}}_{\text {operational costs }} .
\end{aligned}
$$

\section{Numerical Example}

For analysing the optimization model and its impact on shareholder profit gain, the numerical example is taken to illustrate the applicability of proposed model. The aim of the model is to show how traceability optimization helps the firms to optimize economic batch size such that expected loss to shareholder profit is minimum while controlling the other operational costs. Table 2 shows the input parameters of the model used for simulation analysis.

To proposed model is solved using LINGO to obtain optimal solution. The expected loss to shareholders profit is found to be $\$ 14,400.00$ with $5 \%$ probability of recall in next period with optimal batch size equal to 1314 while setup cost, holding cost, and material costs are $\$ 1341.28, \$ 1267.00$, and $\$ 37,800.00$, respectively. We also simulate the model to analyse the impact of batch sizes on operational costs, recall cost, and loss to shareholders wealth. The simulation results show that recall cost can be reduced by minimizing the batch dispersion. Figure 4 also reveals that recall cost increases with the size of batch while operational cost (setup 


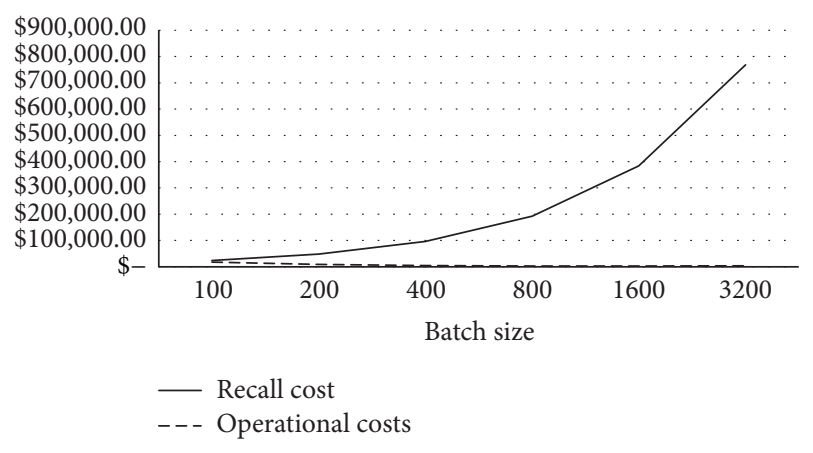

FIGURE 4: Recall cost and operational costs under different batch sizes.

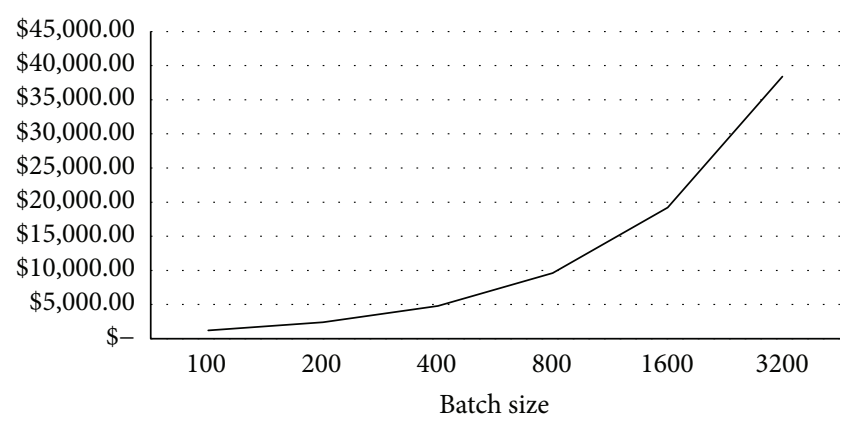

— Expected loss to shareholders

Figure 5: Expected loss to shareholders profit under different batch sizes.

cost and holding cost) reduces with batch size. This is because many direct recall costs depend on size of batch (such as logistics and holding costs). This shows that firms need to be cautioned when selecting the optimum batch size because a larger batch size may be difficult to handle in a recall crisis. On the other hand, it is obvious that an increment in batch size also increases the setup cost, which means a reduction in production efficiency; however, setup cost is negligible as compared to recall cost. This analysis will be important for practitioners because production managers always think that reduction in batch size will increase setup cost on a large scale, whereas analysis shows that setup cost is much lower than recall cost.

It is also determined that stock price of a firm reduces after the announcement of a recall. Figure 5 shows that loss to shareholder profit depends on batch size, because recall cost is also imposed on shareholders after recall announcement. It also reveals that firms may not survive during a recall crisis if batch size is too large and may go bankrupt if the recall size is too large for it to handle. Therefore, firms should analyse the stock price when optimizing the batch sizes because analysis results show that larger batch sizes reduce stock prices dramatically.

This analysis shows that a firm should not only consider the operational costs for batch size optimization, but also incorporate loss of expected profit during a recall crisis. Firms may also select the level of traceability depending

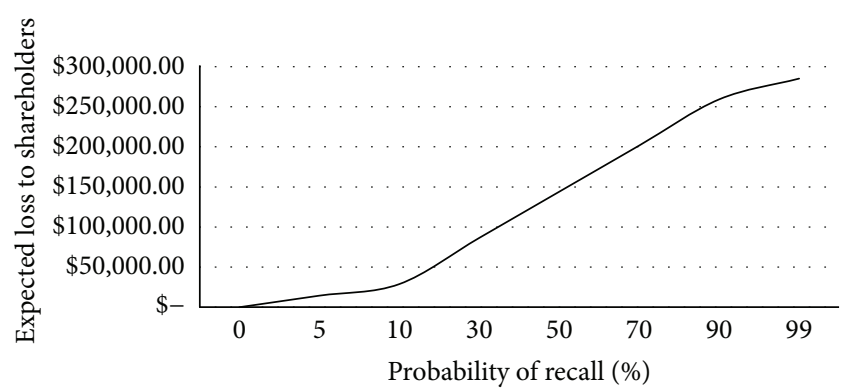

Figure 6: Expected loss to shareholders profit under different recall probabilities.

TABLE 3: Correlation analysis of operational costs and recall cost.

\begin{tabular}{lcccc}
\hline & $\begin{array}{c}\text { Material } \\
\text { cost }\end{array}$ & $\begin{array}{c}\text { Holding } \\
\text { cost }\end{array}$ & Setup cost & Recall cost \\
\hline Material cost & 1.00 & & & \\
Holding cost & 0.97 & 1.00 & & \\
Setup cost & -0.75 & -0.72 & 1.00 & \\
Recall cost & 0.97 & 0.96 & -0.59 & 1.00 \\
\hline
\end{tabular}

on their available resources and its impact on financial loss during recall crisis. We can see that expected loss to shareholder is much less under low probability of recall, that is, under a higher traceability level (see Figure 6). Implementation of a traceability system also depends on other operational costs such as setup costs and inventory holding costs because higher traceability level, on one hand, reduces the profit loss during recall crisis, while on the other hand it increases the setup cost. Therefore, it is also necessary to analyse operational costs impact with respect to the level of traceability. Hence, correlation analysis (see Table 3 ) of various operational costs and recall costs is also added to further analyse the impact of traceability system on firm's performance and shareholder profit.

Correlation analysis shows that an increase in the level of traceability will also increase setup cost; hence operational performance may be effected. Material cost and recall cost are directly correlated. This shows that an increase in batch size will result in wastage in raw material in the case of a recall crisis, similar case to the holding cost. At this stage, it is clear that the only factor to be taken in account when deciding for level of traceability is setup cost. The example data in this paper reveals that setup cost is much lower than the recall cost (as shown in Figure 4) and it is also possible in a real case scenario; therefore decision makers should analyse recall cost, setup cost, and probability of recall when deciding the batch size.

Operational efficiency depends on unit setup cost of production batch. The cost base analysis in this research reveals that if production setup cost is low then manufacturers should only analyse the probability of recall. However, it is not easy to analyse the probability of recall, but it can 
be assessed by past recall data and the reasons of the recalls. Also, the probability of a recall can be assessed by analysing the recalls of similar manufacturers. On the other hand, if production setup cost is high then manufactures have to trade off between setup cost and recall cost which is linked with profit. The model used in this paper shows that recall cost is based on size of finished product batches: larger batch size reduces the setup cost while it increases the recall cost and, hence, potentially affects large number of consumers.

\section{Conclusion}

This paper gives insights about the impact of product recall under various different traceability level on a firm's shareholder's profit. The paper proposed an integrated optimization model to minimize the expected loss to shareholders in recall crisis using batch dispersion methodology. The paper analyses the batch sizes and level of traceability on shareholder profit. It is concluded from experiments that batch size is directly proportional to expected recall cost and larger batch size means more customers will be affected by tainted products and more loss to shareholders profit.

The results of this study are very helpful for practitioners to improve the practices in the industry. The research results show the importance of recall cost minimization in order to withstand in recall crises, because recall cost is imposed on shareholders after recall announcement. Analysis shows that increase in level of traceability (i.e., minimizing probability of recall) will also reduce the operational efficiency, while expected recall cost can be minimized. This may cease the implementation of batch dispersion methodology for minimizing the expected recall cost, because practitioners will perceive too much reduction in production efficiency. For this reason, we also added correlation analysis of various operational costs and recall cost, and the results show that setup cost and recall costs are negatively correlated. This means that reduction in the level of traceability (increment in dispersion) will reduce the production costs but, on the other hand, increase recall cost. However, the experimental results in this paper show that setup cost is much lower than expected with respect to recall costs, which is normally true in all types of industries. This shows that practitioners should focus more on expected recall costs and probability of recall, when designing production system and deciding optimum batch size.

As this study is the first one that integrates traceability optimization based production system and shareholders profit considering recall cost, there are some limitations which leads to future research. In this study a deterministic situation is assumed; however, in practice many parameters follow stochastic behaviour. This requires future research to consider stochastic modelling techniques. Furthermore, it is useful to consider some risk modelling techniques to estimate the probability of recall. Another future direction is to consider impact of timely recall on stock price and shareholders losses.

\section{Notations of Traceability Model}

Indices

$i$ : Raw material batches

$j$ : Component batches

$f$ : Finished product batches.

\section{Parameters}

D: $\quad$ Demand rate of a product, units/period

$P: \quad$ Production rate for a product, units/period (here $P>D$ )

USC: Unit setup cost in production, \$/setup

$H$ : $\quad$ Inventory holding cost of finished products, \$/unit/period

$x$ : $\quad$ Shipment quantity of products at a regular interval (units/shipment)

$t$ : Time interval between successive shipments

$B_{R C}(K)$ : Proportion of the $K$ th type of raw material used in component batches

$V_{i, k}: \quad$ Unit price of batch $i$ of the $K$ th type of raw materials

$R_{f}$ : $\quad$ Unit transaction price of product

CS: $\quad$ Shipment charges of recalled product (\$/unit/period)

CN: Notification charges of recalled product (\$/period)

$\mathrm{CRH}$ : Cost for holding and disposal of recalled products, \$/unit/period

$Q_{K}$ : Quantity of batch of $K$ th type of raw material

$K: \quad$ Type of raw material.

\section{Decision Variables}

Q: Quantity of a finished product batch

$S: \quad$ Integer variable which is quantity of $K$ th type of raw material batches used in finished product batch $f$

$X r c$ : Binary variable equal to 1 if the type of raw material batch $i$ is used in the component batch $j$ and 0 otherwise

$X c f$ : Binary variable equal to 1 if the component batch $j$ is used in the finished product batch $f$ and 0 otherwise

$n$ : Integer variable which is the frequency of product shipments, numbers/period.

\section{Conflict of Interests}

The authors declare that there is no conflict of interests regarding the publication of this paper. 


\section{Acknowledgments}

This research was supported by Basic Science Research Program through the National Research Foundation of Korea (NRF) funded by the Ministry of Education, Science and Technology (2014R1A1A2056338).

\section{References}

[1] USDA, "Recall Summary for Calendar Year 2012," 2012, http://www.fsis.usda.gov/wps/portal/fsis/topics/recalls-andpublic-health-alerts/recall-summaries.

[2] FSANZ, Food Recall Statistics, 2013, http://www.foodstandards .gov.au/industry/foodrecalls/recallstats/Pages/default.aspx.

[3] CPSC, "Product Recall Statistics," August 2013, http://www .statisticbrain.com/product-recall-statistics/.

[4] P. Langhorst, "Product Recall Statistics-An FAQ for Manufacturers," August 2007, http://ezinearticles.com/?Product-RecallStatistics-An-FAQ-for-Manufacturers\&id=900367.

[5] J. Gokhale, R. M. Brooks, and V. J. Tremblay, "The effect on stockholder wealth of product recalls and government action: the case of Toyota's accelerator pedal recall," The Quarterly Review of Economics and Finance, vol. 54, no. 4, pp. 521-528, 2014.

[6] O. Kini, J. Shenoy, and V. Subramaniam, "On the Determinants, Financial and Operating Consequences, and the Product Market Effects of Product Recalls," Financial and Operating Consequences, and the Product Market Effects of Product Recalls, 2013.

[7] H. Shin, R. Richardson, and O. Soluade, "Assessing sales loss from automobile recalls: a Toyota case study," International Journal of Business Continuity and Risk Management, vol. 5, no. 1, pp. 14-28, 2014.

[8] S. Kumar and S. Schmitz, "Managing recalls in a consumer product supply chain-root cause analysis and measures to mitigate risks," International Journal of Production Research, vol. 49, no. 1, pp. 235-253, 2011.

[9] M. Resende-Filho and B. Buhr, "Economics of traceability for mitigation of food recall costs," 2010, https://ssrn.com/ abstract $=995335$.

[10] J. A. Alfaro and L. A. Rábade, “Traceability as a strategic tool to improve inventory management: a case study in the food industry," International Journal of Production Economics, vol. 118, no. 1, pp. 104-110, 2009.

[11] J. Philips, Consumer Product Recalls Prompt Product Visibility Questions, vol. 157, Textile World, Atlanta, Ga, USA, 2007.

[12] C. Zang and Y. Fan, "Complex event processing in enterprise information systems based on RFID," Enterprise Information Systems, vol. 1, no. 1, pp. 3-23, 2007.

[13] P. M. Ferrier and J. C. Buzby, "The economic efficiency of sampling size: the case of beef trim," Risk Analysis, vol. 33, no. 3, pp. 368-384, 2013.

[14] J. Z. Ni, B. B. Flynn, and F. R. Jacobs, "Impact of product recall announcements on retailers' financial value," International Journal of Production Economics, vol. 153, pp. 309-322, 2014.

[15] C. Dupuy, V. Botta-Genoulaz, and A. Guinet, "Batch dispersion model to optimise traceability in food industry," Journal of Food Engineering, vol. 70, no. 3, pp. 333-339, 2005.

[16] X. Wang, D. Li, and C. O’Brien, “Optimisation of traceability and operations planning: an integrated model for perishable food production," International Journal of Production Research, vol. 47, no. 11, pp. 2865-2886, 2009.

[17] A. Rong and M. Grunow, "A methodology for controlling dispersion in food production and distribution," OR Spectrum, vol. 32, no. 4, pp. 957-978, 2010.

[18] M. S. Memon, Y. H. Lee, S. I. Mari, and S. Y. Cho, “Traceability optimization for product safety in supply chain management," in Proceedings of the 8th International Congress on Logistics and SCM Systems (ICLS '13), pp. 55-64, Tokyo, Japan, August 2013.

[19] J. Swait, T. Erdem, and T. Peters, "Shocks to brand equity: an information economics perspective on the US auto industry 2006-2011," Customer Needs and Solutions, vol. 1, no. 4, pp. 317$332,2014$.

[20] S. Freedman, M. Kearney, and M. Lederman, "Product recalls, imperfect information, and spillover effects: lessons from the consumer response to the 2007 toy recalls," Review of Economics and Statistics, vol. 94, no. 2, pp. 499-516, 2012.

[21] Y. Chen and N. H. Nguyen, "Stock price and analyst earnings forecast around product recall announcements," International Journal of Economics and Finance, vol. 5, no. 6, 2013.

[22] R. V. Kübler and S. Albers, "The impact of product recall communication on brand image, brand attitude and perceived product quality," SSRN Electronic Journal, 2012.

[23] Y. Chen, S. Ganesan, and Y. Liu, "Does a firm's product-recall strategy affect Its financial value? An examination of strategic alternatives during product-harm crises," Journal of Marketing, vol. 73, no. 6, pp. 214-226, 2009.

[24] D. Pyke and C. S. Tang, "How to mitigate product safety risks proactively? Process, challenges and opportunities," International Journal of Logistics Research and Applications, vol. 13, no. 4, pp. 243-256, 2010.

[25] X. Wang, D. Li, C. O'brien, and Y. Li, "A production planning model to reduce risk and improve operations management," International Journal of Production Economics, vol. 124, no. 2, pp. 463-474, 2010.

[26] R. D. Marcus, S. Swidler, and T. L. Zivney, "An explanation of why shareholders' losses are so large after drug recalls," Managerial and Decision Economics, vol. 8, no. 4, pp. 295-300, 1987.

[27] R. Saltini and R. Akkerman, "Testing improvements in the chocolate traceability system: impact on product recalls and production efficiency," Food Control, vol. 23, no. 1, pp. 221-226, 2012.

[28] M. H. Cassin, A. M. Lammerding, E. C. D. Todd, W. Ross, and R. S. McColl, "Quantitative risk assessment for Escherichia coli O157:H7 in ground beef hamburgers," International Journal of Food Microbiology, vol. 41, no. 1, pp. 21-44, 1998.

[29] F. Dabbene, P. Gay, and C. Tortia, "Traceability issues in food supply chain management: a review," Biosystems Engineering, vol. 120, pp. 65-80, 2014. 


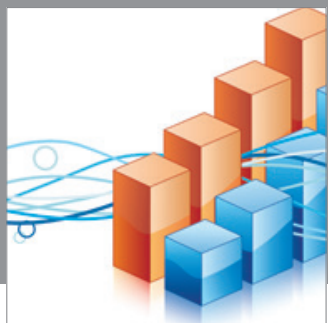

Advances in

Operations Research

mansans

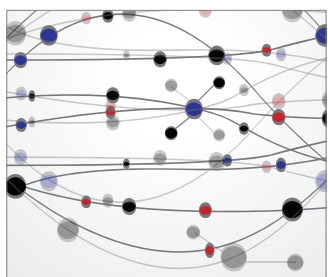

The Scientific World Journal
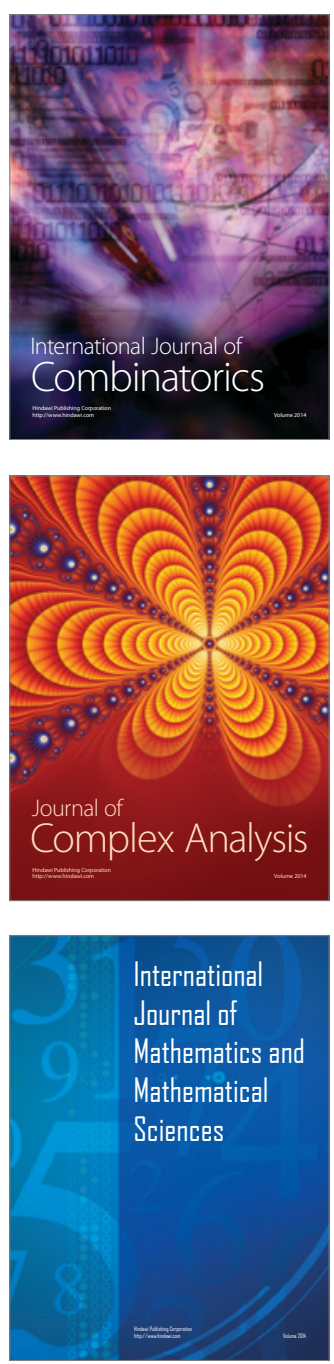
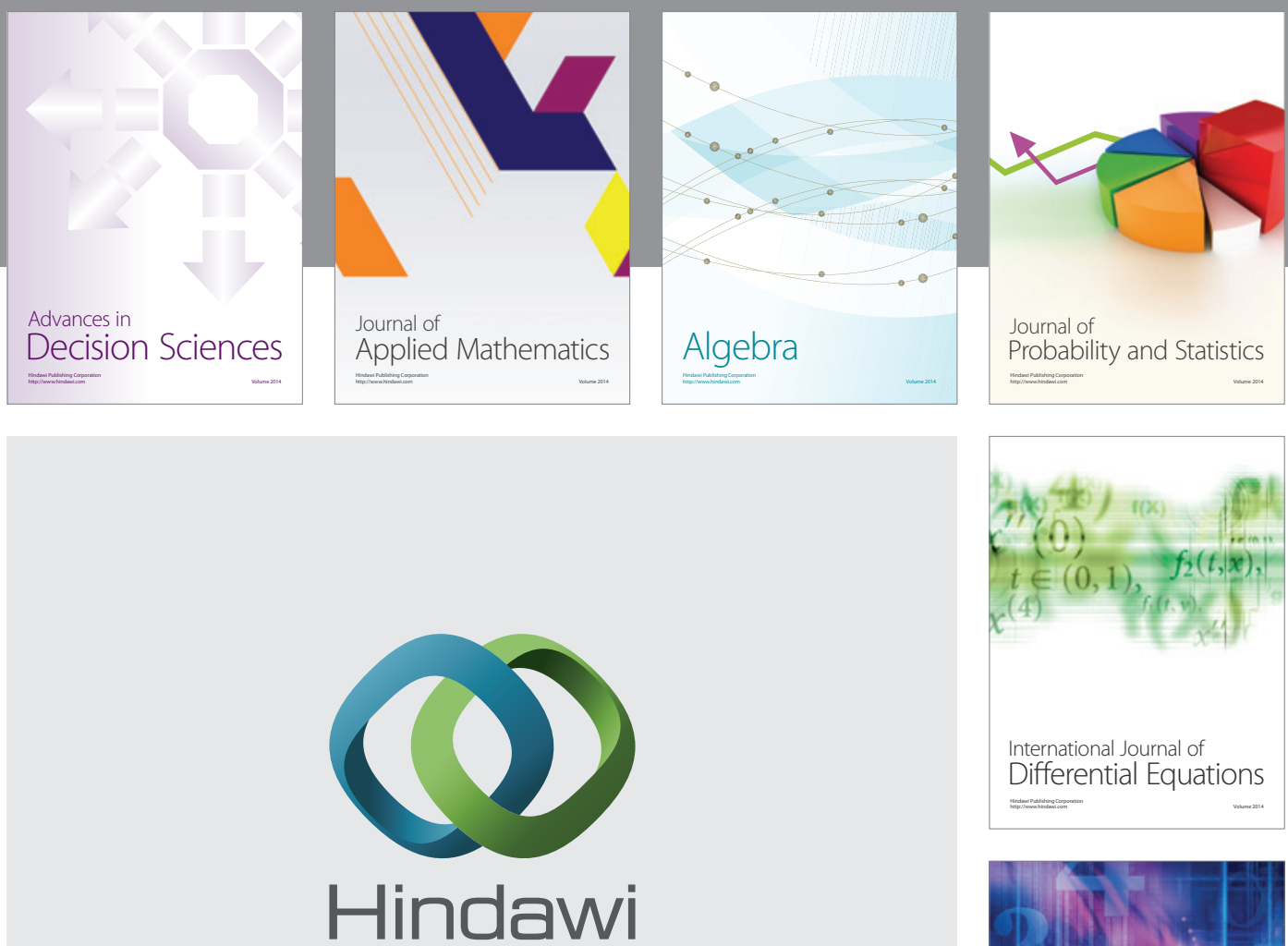

Submit your manuscripts at http://www.hindawi.com
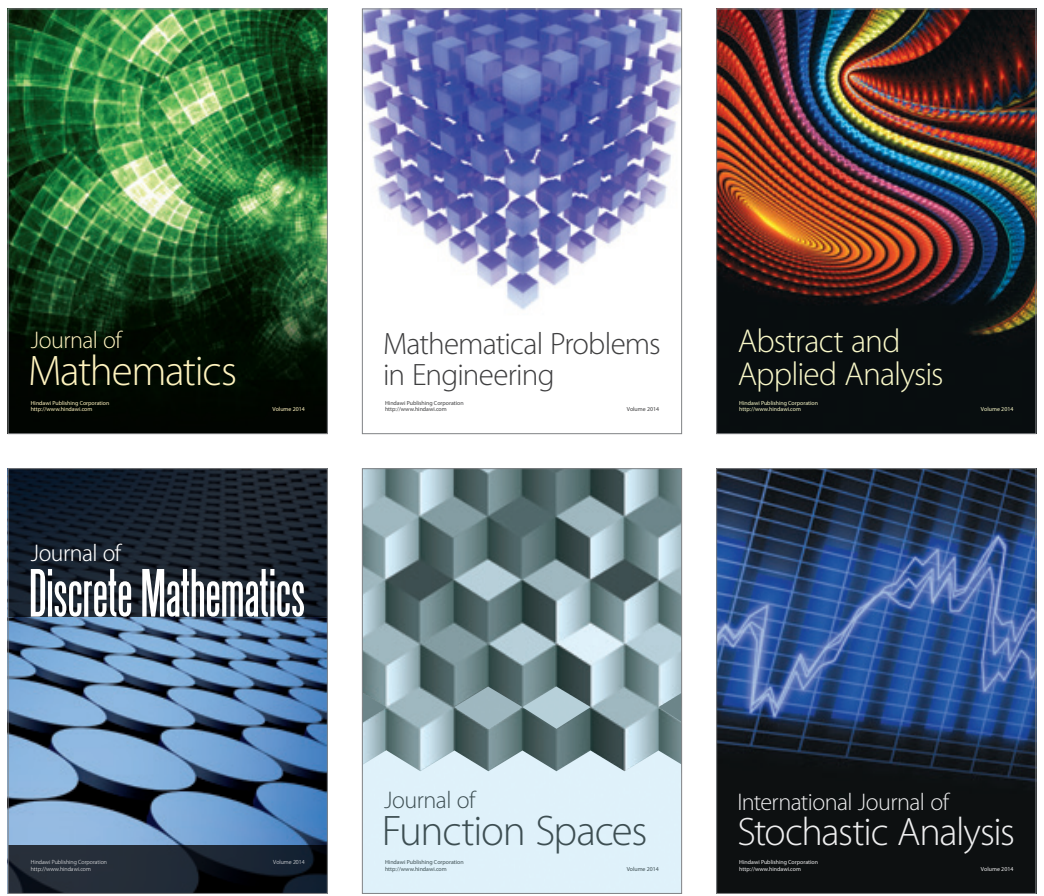

Journal of

Function Spaces

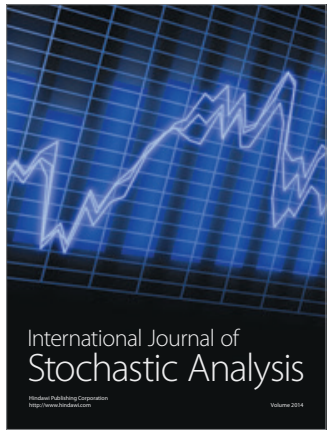

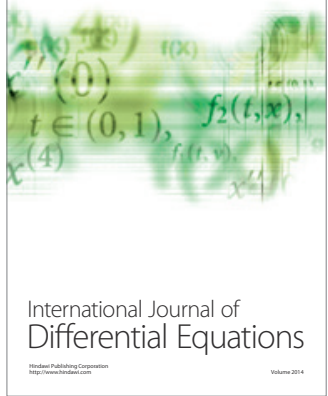
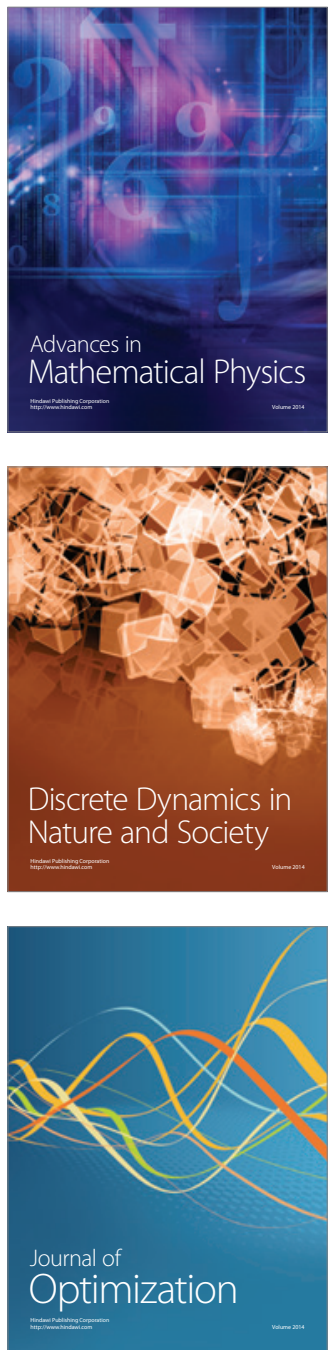